
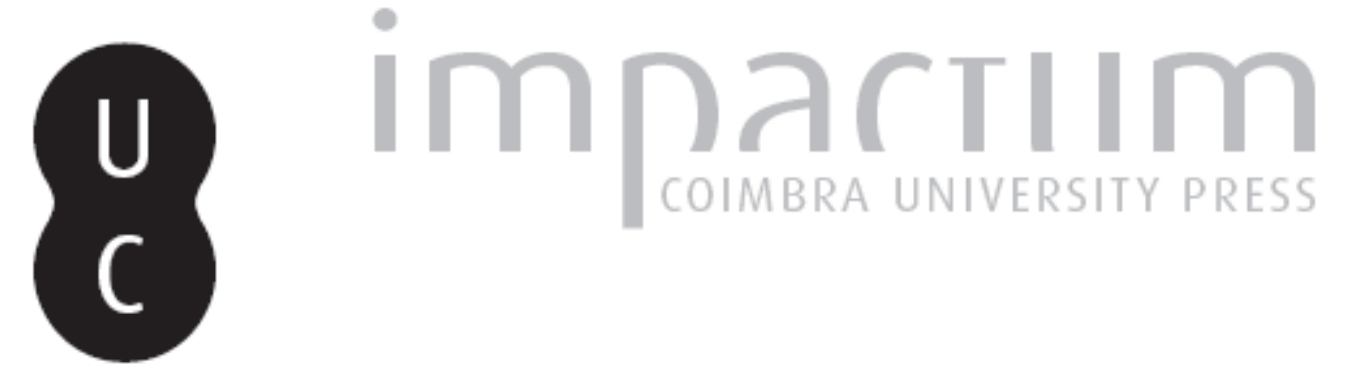

\title{
Estação arqueológica da Horta do Crespo: (Alcácer do Sal)
}

Autor(es): $\quad$ Faria, João Carlos L.; Ferreira, Marisol A.

Publicado por: Imprensa da Universidade de Coimbra

URL persistente:

URl:http://hdl.handle.net/10316.2/45496

DOI:

DOl:https://dx.doi.org/10.14195/1647-8657_32_33_22

Accessed : $\quad$ 26-Apr-2023 14:41:38

A navegação consulta e descarregamento dos títulos inseridos nas Bibliotecas Digitais UC Digitalis, UC Pombalina e UC Impactum, pressupõem a aceitação plena e sem reservas dos Termos e Condições de Uso destas Bibliotecas Digitais, disponíveis em https://digitalis.uc.pt/pt-pt/termos.

Conforme exposto nos referidos Termos e Condições de Uso, o descarregamento de títulos de acesso restrito requer uma licença válida de autorização devendo o utilizador aceder ao(s) documento(s) a partir de um endereço de IP da instituição detentora da supramencionada licença.

Ao utilizador é apenas permitido o descarregamento para uso pessoal, pelo que o emprego do(s) título(s) descarregado(s) para outro fim, designadamente comercial, carece de autorização do respetivo autor ou editor da obra.

Na medida em que todas as obras da UC Digitalis se encontram protegidas pelo Código do Direito de Autor e Direitos Conexos e demais legislação aplicável, toda a cópia, parcial ou total, deste documento, nos casos em que é legalmente admitida, deverá conter ou fazer-se acompanhar por este aviso.

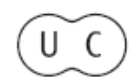




\section{UNIVERSIDADE DE COIMBRA \\ FACULDADE DE LETRAS}

\section{CONIMBRIGA}

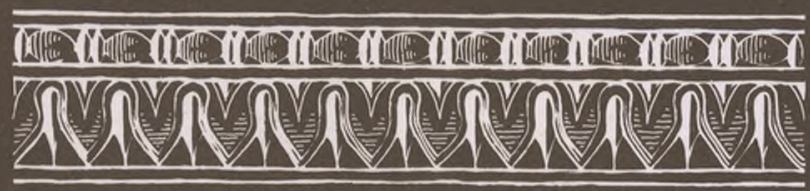

VOLUMES XXXII-XXXIII-1993/94 


\section{Jỗo Carlos L. Faria}

Conservador do Museu Municipal de Alcácer do Sal

\section{MARISOL A. FERreira}

Arqueóloga. Técnica-Superior da Câmara Municipal de Grândola

\section{ESTAÇÃO ARQUEOLÓGICA DA HORTA DO CRESPO}

(ALCÁCER DO SAL)

«Conimbriga» XXXII-XXXIII (1993-1994), p. 349-

RESUMO: Os autores dão conta de uma escavação na Horta do Crespo, a cerca de um quilómetro a norte de Alcácer do Sal. Trata-se possivelmente de uma villa, da qual foram apenas postos a descoberto alguns compartimentos. Publica-se uma selecção de material recolhido, datável do séc. I ao IV d. C.

Summary: AU nord de Salacia (Alcácer do Sal), les auteurs ont fouillé partiellement la pars rustica d'une villa. Le matériel ramassé, dont on publie ici un choix, date du 1er jusqu'au IVe siècle après J. Ch. 
(Página deixada propositadamente em branco) 


\section{ESTAÇÃO ARQUEOLÓGICA DA HORTA DO CRESPO (ALCÁCER DO SAL)}

Situada a pouco mais de $1 \mathrm{Km}$ da vila de Alcácer do Sal, para norte, esta estação arqueológica é conhecida desde 1986, altura em que por nós foi identificada 0 .

Os trabalhos arqueológicos realizados nos finais de 1991, na Horta do Crespo, tiveram como objectivo não só a concretização de sondagens mas também a escavação em extensão de algumas zonas consideradas prioritárias.

Esta intervenção, superiormente autorizada, destinava-se a salvar o máximo possível de testemunhos arqueológicos, bem assim como efectuar o levantamento e registo de todas as estruturas encontradas.

Toda a área de intervenção iria ser posteriormente urbanizada e por isso impunha-se o salvamento imediato daquilo que em nosso entender poderá corresponder à pars rustica de uma villa urbana do período romano, situada nas imediações da Salacia Imperatoria.

$\mathrm{Na}$ escolha da área a escavar, tivemos em consideração as zonas que seriam destinadas à construção de moradias.

A área de intervenção foi dividida em quadrículas de $25 \mathrm{~m}^{2}$ cada, orientadas N-S/E-W (Nmg), formando sectores (A a Z), tendo sido escavados os sectores $\mathrm{E}, \mathrm{F}, \mathrm{G}$ e $\mathrm{H}$.

O sítio arqueológico em causa havia sido bastante destruído nos anos cinquenta deste século, procedendo-se, nessa altura, a terraplanagens que muito o danificaram.

$\left.\mathrm{C}^{1}\right)$ João Carlos L. Faria, Marisol A. Ferreira, Estações inéditas da época romana do concelho de Alcácer do Sal - Breve notícia, Conimbriga, XXV, 1986, p. 44. Possui as seguintes coordenadas: X 166, 9; Y 156, 9 (C.M P. f. 476). 
Por este motivo, os escassos vestígios encontrados não vão muito além dos $30 \mathrm{~cm}$ de profundidade, proporcionando este facto, a rápida progressão dos trabalhos e a consequente colocação à vista de estruturas arqueológicas diversas bem como a recolha de algum espólio.

SECTOR E - Camada única, de terra cinzenta escura, compacta.

Aparecimento de dois compartimentos, notando-se num deles a existência de uma pequena lareira, com fundo de lateres, adossada a uma parede, com grande dispersão de cinzas e carvões.

No compartimento contíguo a este, detectou-se a presença de um pavimento de lateres bastante danificado.

Os muros são constituídos por pedra calcária e pequenos fragmentos de tijolo (lateres), encontrando-se, durante a nossa intervenção, grande quantidade de imbrices fragmentados, dispersos por todo o sector.

SECTOR F - Única camada arqueológica, de terra cinzenta escura, a exemplo do que aconteceu para o sector anteriormente descrito.

Surgimento de compartimento, com muros construídos de pedra calcária e com grande dispersão de lateres e imbrices.

Imediatamente contíguo a esta divisão, escavou-se parte de um tanque com fundo revestido de opus Signinum.

SECTOR G/H - Continuação do aparecimento da única camada arqueológica que detectamos durante a escavação do sítio e já referida para os sectores E e F.

Escavação de dois compartimentos formados por muros de pedra calcária e fragmentos de lateres.

Num deles, a um canto, encontrou-se uma pequena lareira constituída por vários seixos fragmentados pela acção do fogo.

Contíguo a este compartimento, escavámos outra sala, de pequenas dimensões onde se detectou a presença de grande quantidade de pesos de tear em cerâmica comum, alinhados.

\section{CATÁlogo:}

$\mathrm{N}^{\circ} 1$ - (SECTOR F) - Fragmento de garrafa, tipo Isings 50a. Vidro transparente verde-gelo com pequeníssimas bolhas de ar no gargalo.

Gargalo tronco-cónico. Bordo repuxado para fora e depois revirado para si mesmo, um pouco achatado na parte superior. Asa de fita multinervurada.

Cronologia: séc.I em diante. 
$\mathrm{N}^{\circ} 2$ - (SECTOR E) - Lucerna intacta do tipo Dressel-Lamboglia, 30B. Pasta beije, medianamente dura. Engobe castanho.

Orla arredondada e descaída ornamentada com pérolas. Disco liso cercado por uma grossa moldura e com orifício de enchimento pouco centrado. Base de fundo ligeiramente côncavo demarcada por um anel muito baixo. Asa de fita com olhai bastante largo. Bico com evidentes sinais de utilização.

Altura: $42 \mathrm{~mm}$

Diâmetro: $45 \mathrm{~mm}$

Comprimento: $74 \mathrm{~mm}$

Cronologia: Finais do séc. Ill d. C., inícios do séc. IV d. C.

$\mathrm{N}^{\circ} 3$ - (SECTOR E) - Fragmento de bordo de terra sigillata sudgálica, da forma Dragendorff 35 .

Pasta vermelha alaranjada; verniz vermelho escuro.

Diâmetro: $12 \mathrm{~cm}$.

$\mathrm{N}^{\circ} 4$ - (SECTOR G) - Fragmento de prato em terra sigillata clara D, da forma Hayes 58 (Lamboglia 52 A), de parede em quarto de círculo um pouco alargado e bordo em forma de aba estreita, arredondada e um pouco inclinada para o exterior. Apresenta duas caneluras sobre a face superior da aba.

Cronologia: séc. IV d.C.;

Diâmetro: $27 \mathrm{~cm}$.

$\mathrm{N}^{\circ} 5$ - (SECTOR F) - Fragmento em prato de terra sigillata clara D, da forma Hayes 58 (Lamboglia $52 \mathrm{~A}$ ), de parede em quarto de círculo um pouco alargado e bordo em forma de aba estreita. Apresenta, ainda que pouco perceptíveis, duas caneluras sobre a face superior da aba.

Diâmetro: $30 \mathrm{~cm}$

$\mathrm{N}^{\circ} 6$ - (SECTOR G) - Peso de tear vertical. Forma de paralelepípedo de seç̧ão rectangular. Furo central cilíndrico no topo. Pasta do Sado, semelhante à das ânforas.

$\mathrm{N}^{\circ} 7$ (SECTOR G) - Peso de tear vertical. Forma de paralelepípedo, de secção rectangular. Furo central cilíndrico no topo. Pasta do Sado, semelhante a das ânforas.

$\mathrm{N}^{\circ} 8$ - (SECTOR G) - Peso de tear vertical. Forma de paralelepípedo, de secção quase quadrangular. Furo central praticamente cilíndrico, no topo. Tem uma marca gravada antes da cozedura na face superior. Pasta do Sado.

$\mathrm{N}^{\circ} 9$ - (SECTOR G) - Peso de tear vertical. Forma de paralelepípedo de secção quase quadrangular. Furo central praticamente cilíndrico, no topo. Pasta do Sado

$\mathrm{N}^{\circ} 10$ - (SECTOR H) - Lusitana 2 (Dressel 14/Beltrán IV). Bordo de secção triangular, com a aresta bem marcada, face superior convexa e claros vestígios de assentamento. Pasta dura, compacta, de aspecto folheado, quartzítica e com pequenas micas (Pasta do Sado). Cor bege ou laranja-avermelhado.

Conimbriga, 32-33 (1993-1994), 349-357 
Superfícies exteriores rugosas, alisadas a trapo ou pincel.

Diâmetro: $17 \mathrm{~cm}$.

$\mathrm{N}^{\circ} 11$ - (Sector H) - Idem.

Diâmetro: $16 \mathrm{~cm}$.

$\mathrm{N}^{\circ} 12$ - (Sector H) - Idem.

Diâmetro: $15 \mathrm{~cm}$.

$\mathrm{N}^{\circ} 13$ - (Sector H) - Idem.

Diâmetro: $17 \mathrm{~cm}$.

$\mathrm{N}^{\circ} 14$ - (Sector H) - Lusitana 2. Bordo subtriangular. Face superior convexa e com ressalto a dar-lhes o aspecto de bordo de fita. (Pasta do Sado).

Diâmetro: $16 \mathrm{~cm}$.

$\mathrm{N}^{\circ} \mathbf{1 5}$ - (Sector H) - Idem.

Diâmetro: $19 \mathrm{~cm}$.

$\mathrm{N}^{\circ} 16$ - (Sector F) - Fragmento de bico fundeiro de Lusitana 4 (Almagro $51 \mathrm{C}$ ). Bico fundeiro cilíndrico e oco, com interior em bola. Pasta do Sado.

Superfícies exteriores com aguada, tornando-a mais escura que a pasta.

$\mathrm{N}^{\circ} 17$ - (Sector F) - Marca em relevo, incompleta, Q.C[?], com um ponto triangular de pequeno relevo a separar as duas primeiras letras.

Inscrita numa cartela rectangular, bem impressa, numa ânfora tipo Dressel 20, de secção ovalada. Pasta de tonalidade ocre-rosada, com um ténue cerne ocre-acinzentado, muito depurada, com pequeníssimas areias, micas e partículas negras.

Superfícies alisadas, da tonalidade da pasta.

$\mathrm{N}^{\circ} 18$ - (Sector H) - Alguidar. Troncocònico com bordo pendente e atrombetado. Pasta do Sado.

Diâmetro: $24 \mathrm{~cm}$.

$\mathrm{N}^{\circ} 19$ - (Sector H) - Talha. Bordo engrossado e canelado, corpo sensivelmente ovoide. Pasta bege, micácea, com areias atingindo por vezes $1 \mathrm{~cm}$.

Diâmetro: $30 \mathrm{~cm}$.

$\mathrm{N}^{\circ} \mathbf{2 0}$ - (Sector H) - Idem.

Diâmetro: $34 \mathrm{~cm}$.

$\mathrm{N}^{\circ} 21$ - (Sector F) - Pote. Ombros arredondados e descaídos, bordo amendoado em forma de aba curta, praticamente horizontal. Pasta do Sado.

Superfícies alaranjadas, queimada pela cozedura.

Diâmetro: $12 \mathrm{~cm}$. 
$\mathrm{N}^{\circ} 22$ - (Sector H) - Pote. Ombros quase rectos, a sugerirem um bojo ovoide. Bordo em forma de aba, revirado para fora. Pasta do Sado.

Superfícies bege-alaranjadas muito bem alisadas.

Diâmetro: $34 \mathrm{~cm}$.

$\mathrm{N}^{\circ} 23$ - (Sector F) - Pote. Bojo aparentemente periforme, bordo revirado para fora a formar aba. Pasta quartzo-micácea, de tom alaranjado queimada pela cozedura.

Superfícies idênticas à pasta.

Diâmetro: $16 \mathrm{~cm}$.

$\mathrm{N}^{\circ} 24$ - (Sector H) - Pote. Ombros convergentes, bordo revirado para fora, quase recto. Pasta do Sado.

Superfícies bege-alaranjadas, mais clara do que a pasta.

Diâmetro: $15 \mathrm{~cm}$.

$\mathrm{N}^{\circ} 25$ - (Sector H) - Prato covo. Parede quase recta, ligeiramente inclinada, com grande esvasamento. Pasta do Sado.

Superfícies alaranjadas, mais claras do que a pasta.

Diâmetro: $35 \mathrm{~cm}$.

$\mathrm{N}^{\circ} 26$ - (Sector H) - Idem.

Diâmetro: $34 \mathrm{~cm}$.

$\mathrm{N}^{\circ} 27$ - (Sector F) - Pote. Colo alto, ligeiramente côncavo, bordo em forma de aba curta e soerguida. Pasta do Sado.

Superfícies alaranjadas, queimada pela cozedura.

Diâmetro: $11 \mathrm{~cm}$.

$\mathrm{N}^{\circ} 28$ - (Sector G) - Prato covo. Parede quase recta, ligeiramente ondulada, com grande esvasamento. Pasta alaranjada, com pequenas areias, sem micas visíveis, de aspecto folheado com pequenas fendas.

Superfícies alaranjadas, mais claras do que a pasta.

Diâmetro: $35 \mathrm{~cm}$.

$\mathrm{N}^{\circ} 29$ - (Sector H) - Tigela. Parede arqueada e bordo simples, boleado, ligeiramente revirado para o interior. Pasta do Sado.

Superfícies de cor bege-acastanhada.

Diâmetro: $18 \mathrm{~cm}$

$\mathrm{N}^{\circ} 30$ - (Sector H) - Tigela. Paredes esvasadas e bordo simples, boleado. Pasta do Sado.

Superfície alisada, sem engobe.

Diâmetro: $16 \mathrm{~cm}$.

$\mathrm{N}^{\circ} 31$ - (Sector H) - Terrina? Fundo raso. Copa hemisférica, com um estribo estreito de perfil triangular.

Conimbriga, 32-33 (1993-1994), 349-357 
Superfícies acastanhadas, com engobe. Pasta muito fina, compacta, bastante depurada, de tom rosa.

Diâmetro: $28 \mathrm{~cm}$.

$\mathrm{N}^{\circ} 32$ - (Sector H) - Prato covo. Parede bastante arqueada, bordo simples, ligeiramente boleado e revirado para o interior. Pasta do Sado.

Superfície bege-alaranjada.

Diâmetro: $33 \mathrm{~cm}$.

$\mathrm{N}^{\circ} 33$ - (Sector H) - Bordo de almofariz de copa arqueada e bordo amendoado. Pasta quartzítica esponjosa e superfícies bege-acastanhadas.

Diâmetro: $23 \mathrm{~cm}$.

\section{ALGUMAS CONSIDERAÇÕES}

Um dos primeiros aspectos a reter é o de que o sítio arqueológico ocupava uma área mais vasta, não se confinando apenas ao espaço no qual realizámos a nossa intervenção.

A antiga estrada nacional $n .^{\circ} 5$ por um lado, e as terraplanagens aqui realizadas nos anos cinquenta deste século, viriam a danificar bastante a estação arqueológica em causa.

Outro aspecto a considerar é o de a situação geográfica do sítio, nas proximidades da Salacia Imperatoria, nos levar a crer estarmos em presença de uma villa urbana do período romano, tendo sido escavada, parcialmente, a pars rustica dessa villa.

Por outro lado, e infelizmente, a grande mistura de materiais encontrados apenas numa única camada arqueológica, não permite tirar grandes ilações, apenas podendo ajudar na atribuição de uma cronologia de ocupação do local, o qual, pela análise do espólio encontrado, abrange um período cronológico cultural que se estende desde o séc. I d. C. ao séc. IV d. C. 


\section{BIBLIOGRAFIA}

AlarCão, J. (1968) Vidros romanos de Museus do Alentejo e Algarve, "Conimbriga", VII, p. 7-40.

ALARCÃO, Jorge de (1974), Cerâmica comum local e regional de Conimbriga, Coimbra.

AlarCão, J. (1979), Vidros do Castelo de Alcácer do Sal, "Setúbal Arqueológica", IV, Setúbal, p. 155-170.

AlARCÃO, Jorge de (1983), Portugal Romano, Lisboa.

ALARCÃO, Jorge de (1988), O Domínio Romano em Portugal, Lisboa.

ALMEIDA, J. A. Ferreira de (1952), Introdução ao estudo das lucernas romanas em Portugal, "O Arqueólogo Português", N. S., p. 5-208.

CAllender, M. H. (1965), Roman Amphorae witer index of stamps, Londres.

CHIC GARCIA, Genaro (1985), Epigrafia anforica de la Betica /, Sevilha.

Diogo, A. M. Dias; FARIA, João Carlos Lázaro; FerReIRA, Marisol (1987), Fornos de ânforas de Alcácer do Sal, "Conimbriga", Coimbra, XXVI, p. 77-111

DIOGO, A. M. Dias; FARIA, João Carlos Lázaro (1989), Trabalho e produção no Sado durante a época romana, "Movimento Cultural", 5, Setúbal, p. 81-92.

Diogo, A. M. Dias; FARIA, J. C. L. (1990), Fornos de cerâmica romana no Vale do Sado. Alguns elementos, "As ânforas Lusitanas. Tipologia, Produção, Comércio", Coimbra, p. 173-189.

DiogO, A. M. Dias; FARIA, João Carlos Lázaro (1990), Elementos para a caracterização e periodização da economia do baixo Sado durante a época romana, "Actas do Colóquio Arqueologia Hoje", 1 (Etnoarqueologia), Faro, p. 92-107.

FARIA, João Carlos Lázaro; FerReIRA, Marisol A. (1988), Descoberta de duas sepulturas romanas na vila do Torrão, "Movimento Cultural", 5, Setúbal, p. 29-35.

HAYES, J. N. (1972), Late Roman Pottery, Londres.

NolEN, Jeannette U. Smit (1985), Cerâmica comum de necrópoles do Alto Alentejo, Lisboa.

Nolen, J. (1988), Materiais da villa romana do Alto do Cidreira (Cascais), "Conimbriga") 27, p. 61-140.

Oleiro, J. M. Bairrão (1952), Catálogo das lucernas romanas - Museu Machado de Castro, Coimbra.

SiMÕES, Maria Helena (1986), Vidros romanos do Museu de Castelo Branco, "Conimbriga", XXV, Coimbra, p. 143-152.

Conimbriga, 32-33 (1993-1994), 349-357 

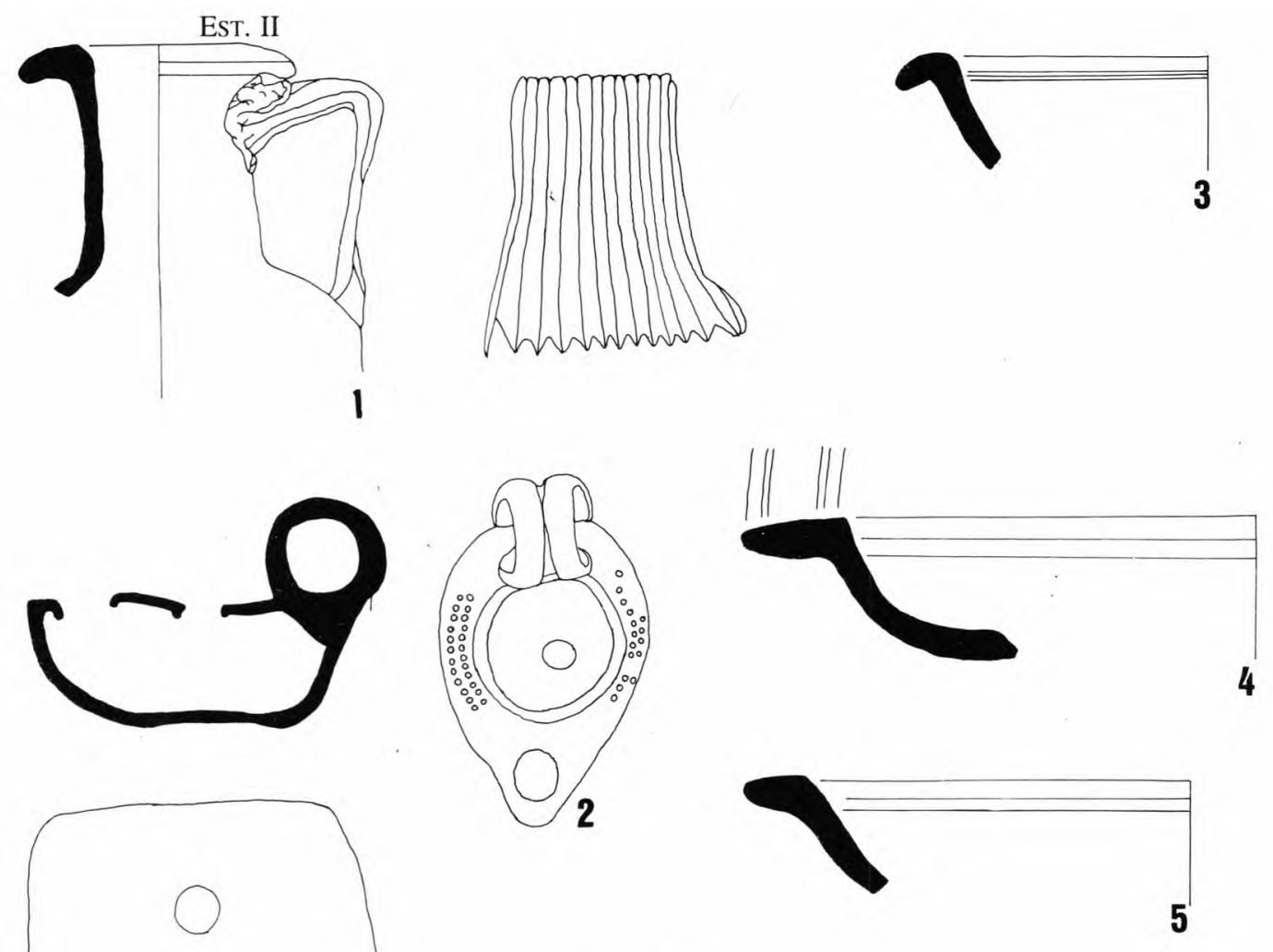

6
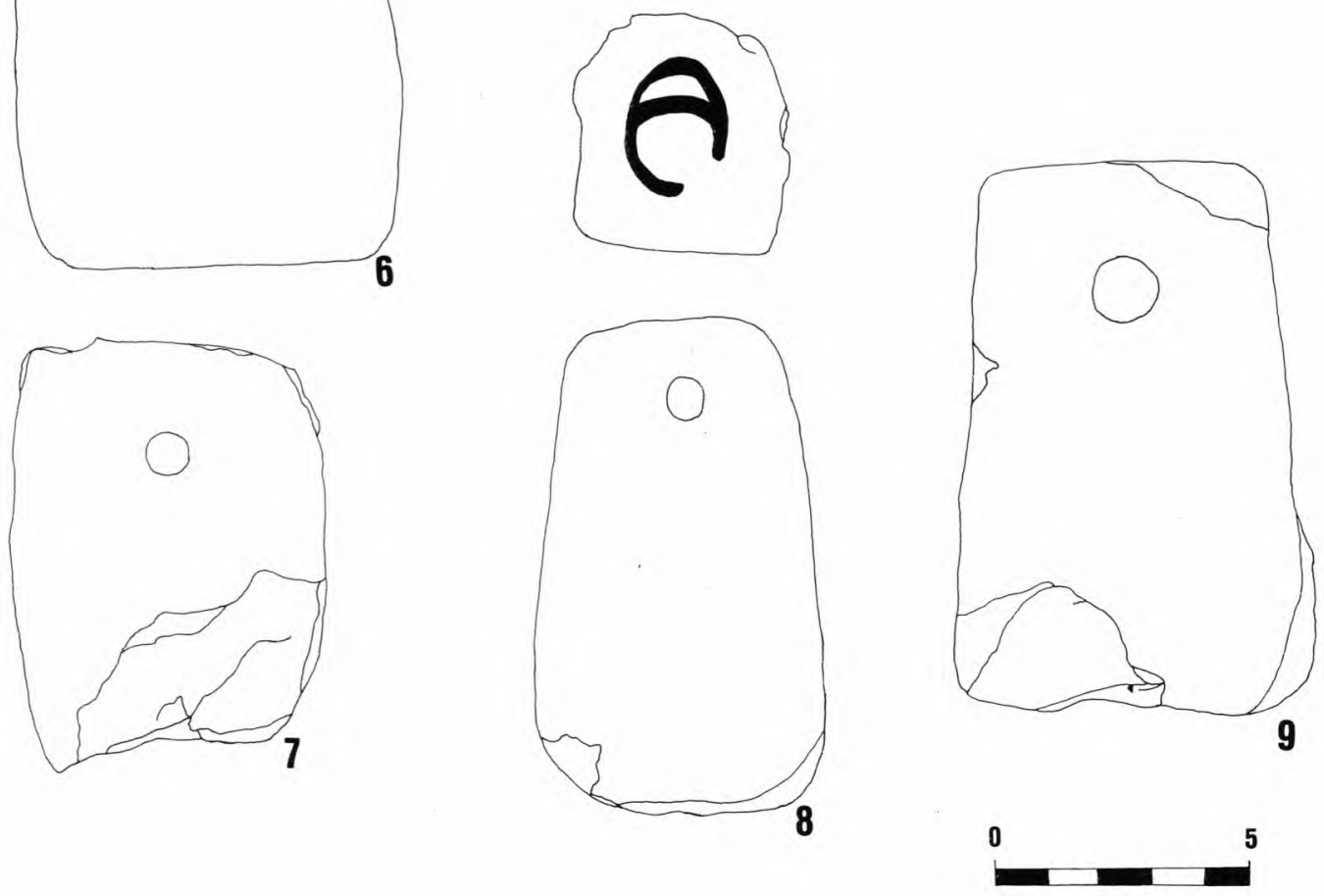


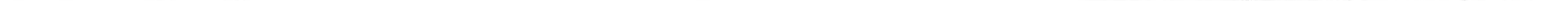


(Página deixada propositadamente em branco) 

EsT. IV
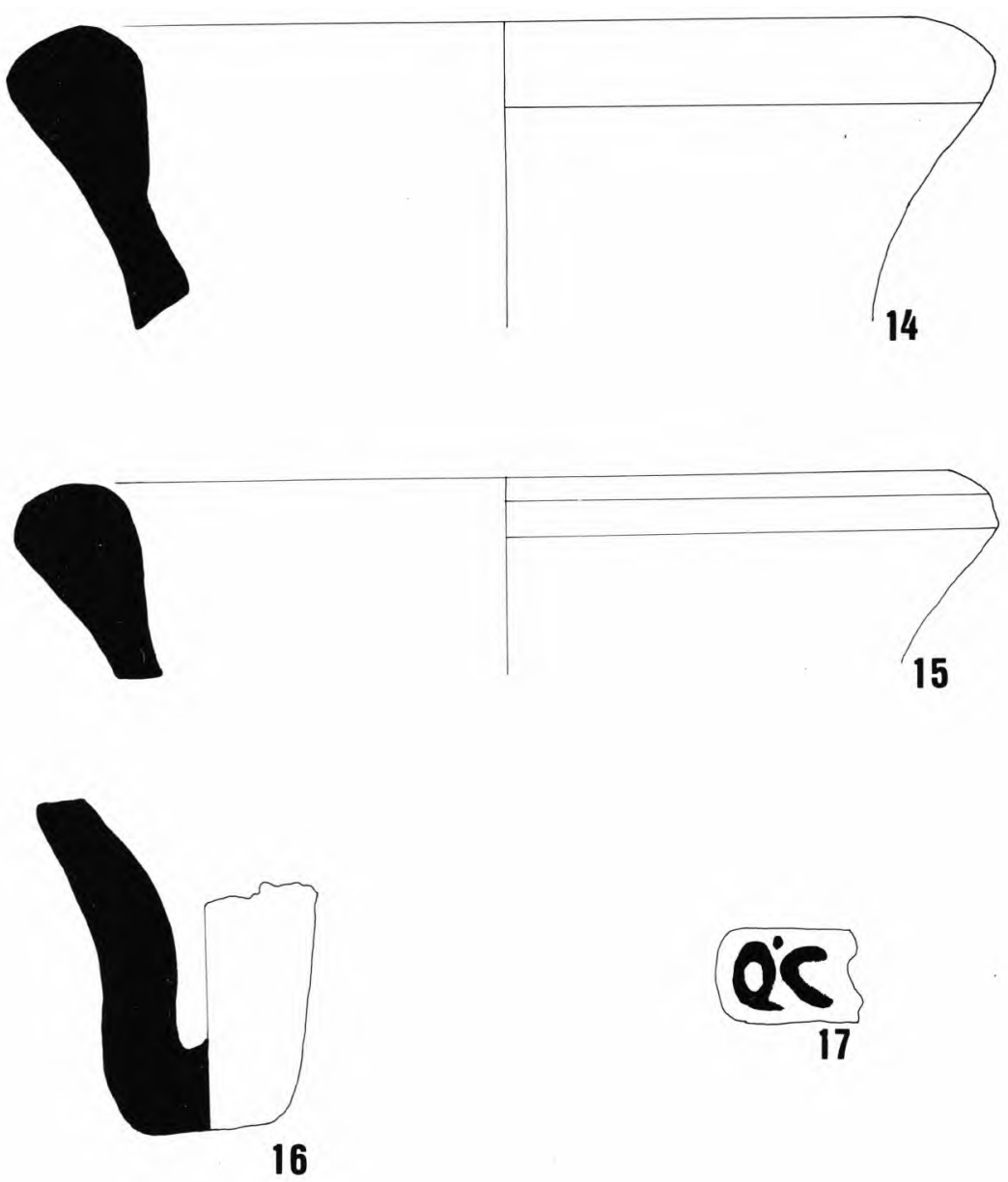

\section{Qce}
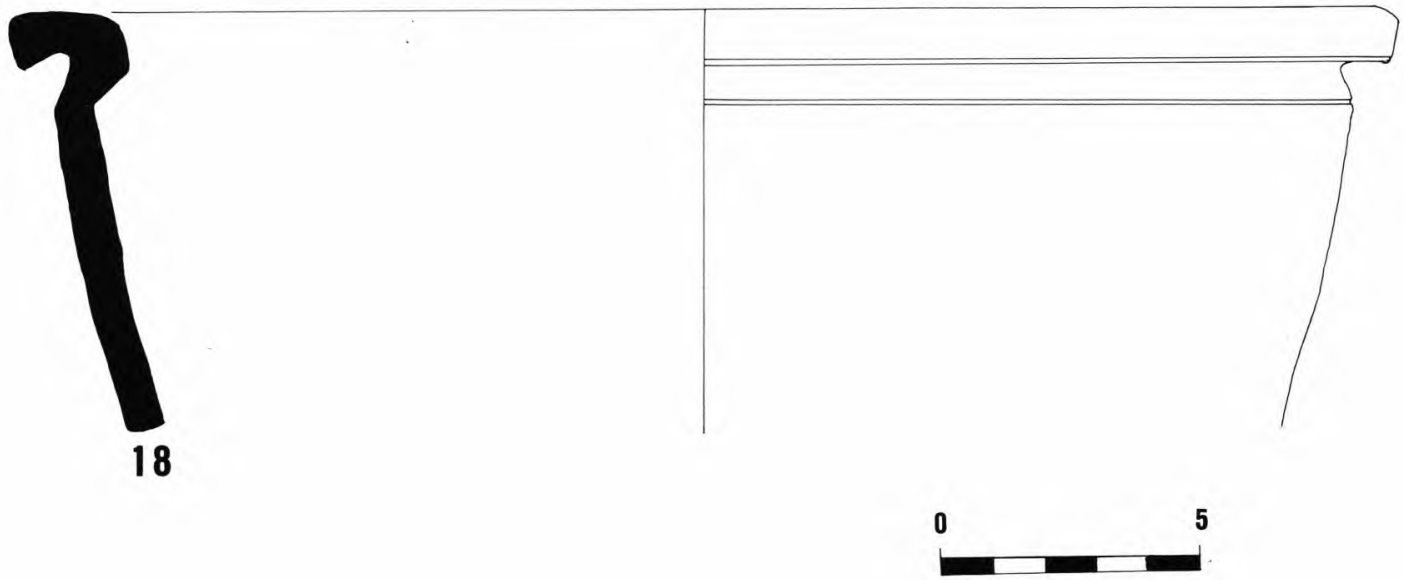
EsT. V
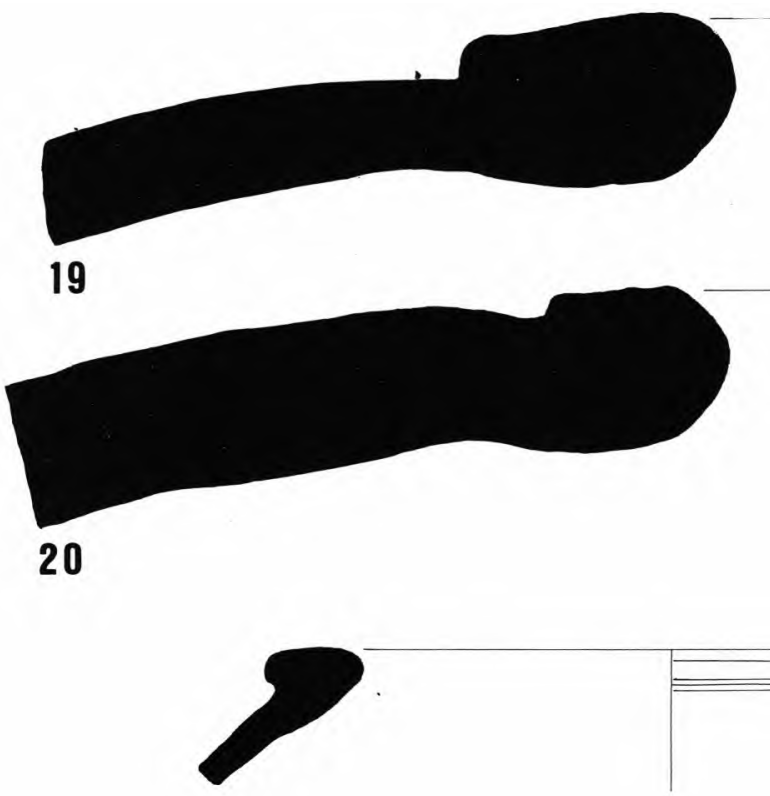

21
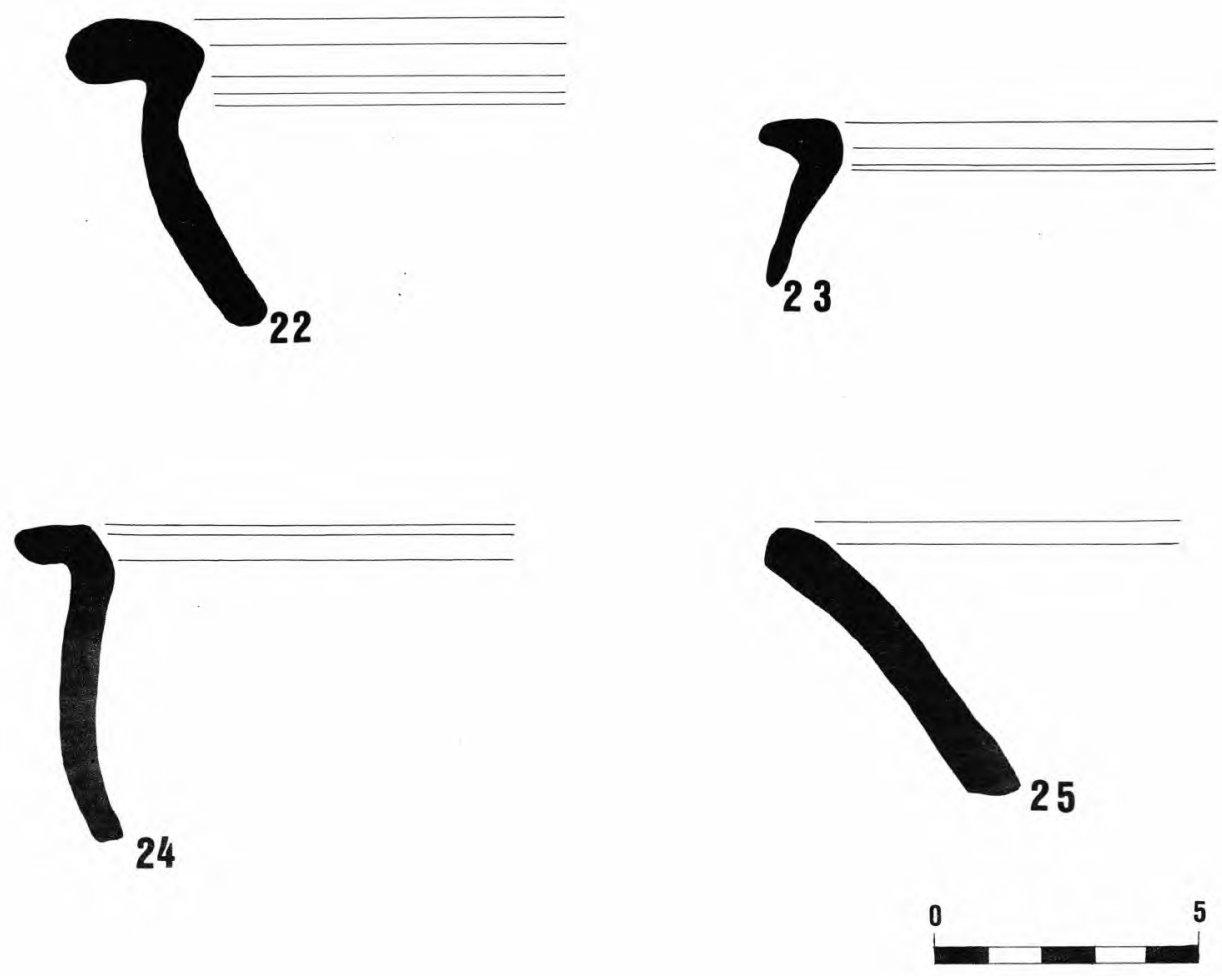
EST. VI

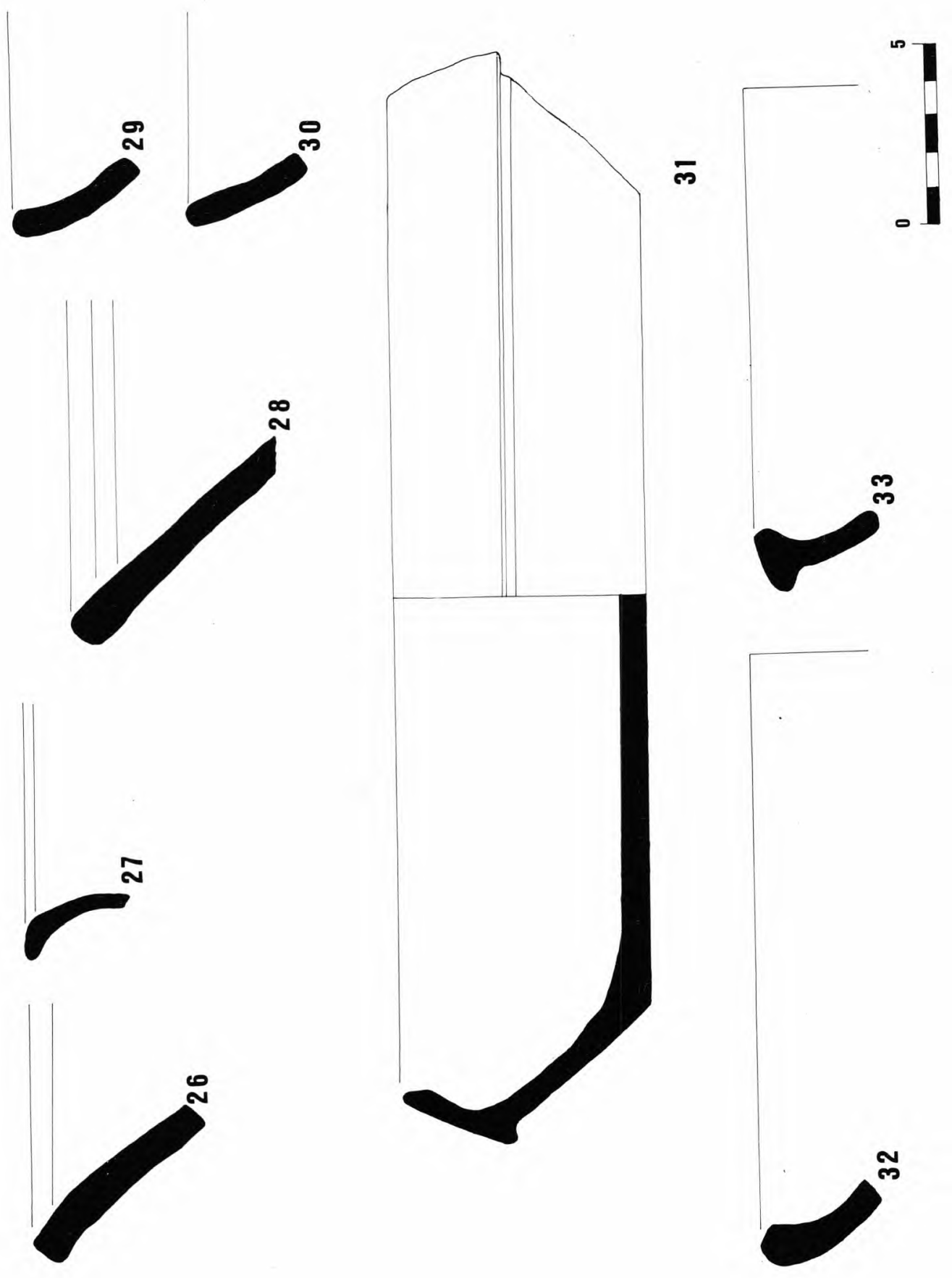

